\title{
Fabrication of Titanium dioxide nanotube photo-electrodes in different electrolyte mixtures and the impacts on their characteristics and photo- -catalytic abilities under visible light
}

\author{
Mohamed Thabit-Huiling Liu*, Jian Zhang, Bing Wang \\ School of Municipal and Environmental Engineering, Harbin Institute of Technology, State Key Laboratory of Urban \\ Water Resource and Environment, 150090 Harbin, China \\ "Corresponding author: e-mail: hlliu2002@163.com
}

\begin{abstract}
$\mathrm{TiO}_{2}$ nanotube arrays were fabricated using electrochemical anodization of titanium foils, where different types of electrolytes were tested to determine conceptual choice for nanotubes fabrication. These electrolytes are $1 \mathrm{M}$ $\left(\mathrm{NH}_{4}\right)_{2} \mathrm{SO}_{4}$ containing $0.5 \%$ wt $\mathrm{NH}_{4} \mathrm{~F}, 1 \mathrm{M} \mathrm{Na} \mathrm{SO}_{4}$ containing $0.5 \%$ wt $\mathrm{NH}_{4} \mathrm{~F}, 1 \mathrm{M} \mathrm{NaF}$ containing $0.5 \%$ wt $\left(\mathrm{NH}_{4}\right)_{2} \mathrm{SO}_{4}$ and a mixture of water: ethylene glycol 1:9 containing $0.5 \%$ wt $\mathrm{NH}_{4} \mathrm{~F}$. The foils were marked as EG type (Ethylene Glycol), AS type (Ammonium sulfate), SS type (sodium sulfate) and SF type (sodium fluoride). The photocatalytic capabilities and characterization of the fabricated NTAs were analyzed using SEM, XRD, and DRS. The degradation ratio of designated organic pollutants (Rhodamine B) was analyzed. The obtained results have proven that foils fabricated using Ethylene glycol have significant photocatalytic abilities, with a degradation ratio of EG-SS-SF-AS types being $80 \%$ to $85 \%, 70 \%$ to $80 \%, 70 \%$ to $75 \%$ and $52 \%$ to $55 \%$, respectively.
\end{abstract}

Keywords: $\mathrm{TiO}_{2}$, anodizing, electrolytes, Nanotube arrays, photo-catalysis, water pollution, water treatments, Rhodamine B.

\section{INTRODUCTION}

The technology of using one-dimensional nanomaterial structures such as nanotubes, nanoflakes, nanorods and nanowires to degrade various types of water pollutants are considered revolutionary, since the discovery of water splitting on the $\mathrm{TiO}_{2}$ surface due to its remarkable photocatalytic capabilities ${ }^{\mathbf{1 - 3}}$, as is shown in the following reactions:

$\mathrm{TiO}_{2}+\mathrm{h} v \rightarrow \mathrm{h}_{V B}{ }^{+}+e_{C B}$

$h_{V B}{ }^{+}+\mathrm{H}_{2} \mathrm{O}_{(a d s)} / \mathrm{OH}_{(a d s)}^{-} \rightarrow \cdot \mathrm{OH}+\mathrm{H}^{+}$

$e_{C B}{ }^{-}+O_{2(a d s)} \rightarrow \cdot O_{2}$

$\cdot \mathrm{O}_{2}^{-}+\mathrm{H}_{2} \mathrm{O} \rightarrow \mathrm{HO}_{2}+\mathrm{OH}^{-}$

$2 \mathrm{HO}_{2} \rightarrow \mathrm{O}_{2}+\mathrm{H}_{2} \mathrm{O}_{2}$

$\mathrm{HO}_{2}+\mathrm{H}_{2} \mathrm{O}+e_{\mathrm{CB}^{-}} \rightarrow \mathrm{H}_{2} \mathrm{O}_{2}+\mathrm{OH}^{-}$

$\mathrm{H}_{2} \mathrm{O}_{2}+e_{\mathrm{CB}}{ }^{-} \rightarrow \cdot \mathrm{OH}+\mathrm{OH}^{-}$

$\mathrm{H}_{2} \mathrm{O}_{2}+\cdot \mathrm{O}_{2}^{-} \rightarrow \cdot \mathrm{OH}+\mathrm{OH}^{-}+\mathrm{O}_{2}$

Much research has been dedicated to enhancing their photocatalytic properties, which aim to significantly increase the efficiency of both organic and non-organic pollutants elimination, air purification and for solar energy production purposes ${ }^{4-6}$. Among these technologies, nanotubes have been found to be an ideal nanostructure, for both light absorbance and charge separation ${ }^{7,8}$, due to their large internal surface area without any concomitant decreasing the geometric and structural order ${ }^{9-10}$. Titanium can be converted into highly ordered $\mathrm{TiO}_{2}$ nanotubes using self-assembly during the anodization process $^{11-13}$. The growth of the structure of the fabricated nanotubes is greatly affected by several parameters such as electrolyte composition, anodization voltage and time ${ }^{11-13}$. $\mathrm{TiO}_{2}$ nanotubes are limited by several defects such as wide band gap $(3.2 \mathrm{eV})^{\mathbf{1 6}}$. The tube structure is a result of the deepening and expansion of small pores and in which the low acidity at the bottom of the pores help to etch the pore into a tubular structure ${ }^{17}$ as is shown in Figure 1.

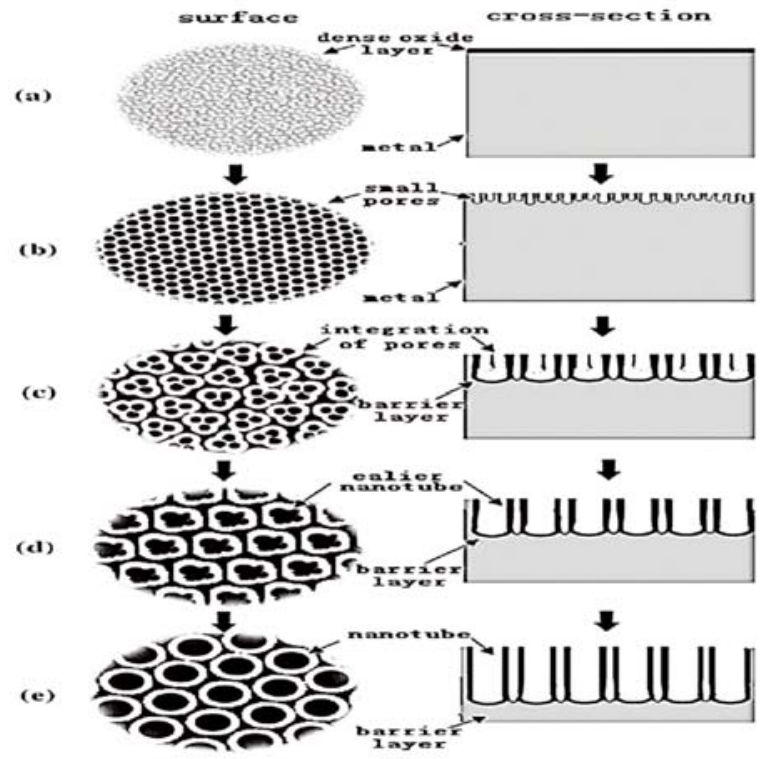

Figure 1. The evolution of straight nanotubes at a constant anodization voltage

$\mathrm{TiO}_{2}$ can only be excited by ultraviolet radiation, as the photocatalytic process has no influence on the degradation process under dark conditions ${ }^{18-20}$. However, in the presence of light, the photocatalytic process is able to greatly enhance the degradation process via accelerating the reaction ${ }^{21-22}$. Light absorption needs to have a certain amount of energy which is in relation to the wavelength of light, in which the light does not contain the required energy to transport electrons from valence band to conduction band ${ }^{23-24}$. Nanotubes show unique physical and chemical properties because they have free spaces in their interiors as well as an outer space that can be filled with active materials. $\mathrm{TiO}_{2}$ acts photocatalically by absorbing light with a wavelength no 
longer than $387 \mathrm{~nm}$ to generate $\mathrm{e}^{-}$and $\mathrm{h}^{+}$driving the reduction and oxidation reaction ${ }^{25}$.

One of the fundamental parameters in the fabrication of the nanotube arrays is the electrolyte, where the performance of several electrolytes compositions and mixtures were reclaimed to produce a satisfactory quality of highly ordered nanotube arrays. Among the numerous types of these electrolytes, four electrolytes have been widely used without significantly distinguishing the core difference between the final product quality and its photocatalytic properties. These mixtures are $1 \mathrm{M}\left(\mathrm{NH}_{4}\right)_{2} \mathrm{SO}_{4}$ containing $0.5 \%$ wt $\mathrm{NH}_{4} \mathrm{~F}^{26}, 1 \mathrm{M} \mathrm{Na}_{2} \mathrm{SO}_{4}$ containing $0.5 \%$ wt $\mathrm{NH}_{4} \mathrm{~F}^{27}, 1 \mathrm{M} \mathrm{NaF}$ containing $0.5 \%$ wt $\left(\mathrm{NH}_{4}\right)_{2} \mathrm{SO}_{4}{ }^{28}$ and a mixture of water: ethylene glycol $1: 9$ containing $0.5 \%$ wt $\mathrm{NH}_{4} \mathrm{~F}^{29}$. Therefore, this study is conducted to investigate the photocatalytic capability and characterization of the fabricated NTAs using the said electrolytes. The nanotubes were analyzed using SEM, $\mathrm{XRD}$, and DRS tests. The degradation ratio of designated organic pollutants (Rhodamine B) as an example of organic pollutants, indicates the overall efficiency of the nanotubes etched on the surface of the titanium foil.

\section{MATERIAL AND METHODS}

\section{Material}

All chemicals used in this study were analytical grade and were employed without further purification. The titanium sheets were purchased from the Baoji and Baoye Titanium-Nickel Manufacturing Co., Ltd. Sodium sulfate $\left(\mathrm{Na}_{2} \mathrm{SO}_{4}\right)$, Sodium Fluoride $(\mathrm{NaF})$, Ammonium Sulfate, Ammonium Fluoride, Ethylene Glycol, acetone, absolute ethanol, Rhoda mine B, Power supply 0 to $30 \mathrm{~V}$ electric potential. Magnetic agitators, $35 \mathrm{~W}$ xenon light source, $50 \times 60 \times 40 \mathrm{~cm}$ light isolation metal box were used for isolating the experiment from external affections.

\section{Photoelectrode preparation}

The size of the strip titanium sheet is $90 \mathrm{~mm} \times 10$ $\mathrm{mm} \times 0.5 \mathrm{~mm}$. The effective work area is $40 \mathrm{~mm} \times$ $10 \mathrm{~mm} \times 0.5 \mathrm{~mm}$. The titanium foils were cleaned via immersing in a mixture of acetone and absolute ethanol than in an ultrasonic water bath for 30 minutes. The foils were left to dry for $1 \mathrm{~h}$ at $80^{\circ} \mathrm{C}$ in vacuum oven. After completely drying the foils were immersed in a mixture of $\mathrm{HF}: \mathrm{HNO}_{3}: \mathrm{H}_{2} \mathrm{O}=1: 4: 5$ in volume for 30 seconds followed by rinsing with D.I water, then dried again in a vacuum oven for $4 \mathrm{~h}$ at $70^{\circ} \mathrm{C}$.

The polished titanium foils were anodized at a constant potential of $2 \mathrm{~V}$ in an electrolyte at room temperature for $2 \mathrm{~h}$ in a two-electrode configuration with a platinum cathode. After anodic oxidation, the samples were rinsed with deionized water and dried in air. The resulting amorphous $\mathrm{TiO}_{2}$ NTs were annealed at $500^{\circ} \mathrm{C}$ for $2 \mathrm{~h}$ with heating and cooling rates of $2^{\circ} \mathrm{C} \mathrm{min}^{-1}$ in air to crystallize the tubes.

\section{Photocatalytic (PC) evaluation}

Photo catalytic activities of the samples were evaluated by using $\mathrm{RhB}$ as a model organic dye pollutant compound. The foils were immersed in a cylindrical quartz photo reactor containing $50 \mathrm{~mL}$ of $\mathrm{RhB}(5 \mathrm{mg} / \mathrm{L})$. The $\mathrm{TiO}_{2}$
NTAs electrode was placed vertically in the reactor then agitated with a magnetic agitator, and when the mixture reaches the point of equilibrium the $35 \mathrm{~W}$ Xenon light was switched on for 20, 40, 60, 80, 100 and 120 minutes. The samples were collected and labeled based on the electrolyte type used in the test then measured at 552 $\mathrm{nm}$ using a UV-vis spectrophotometer. The test was performed inside an isolated metal box (light exposure chamber) with the dimension of $50 \times 60 \times 40 \mathrm{~cm}$. The established equipment inside the isolated metal box (photocatalytic process chamber) are as shown in Figure 2.

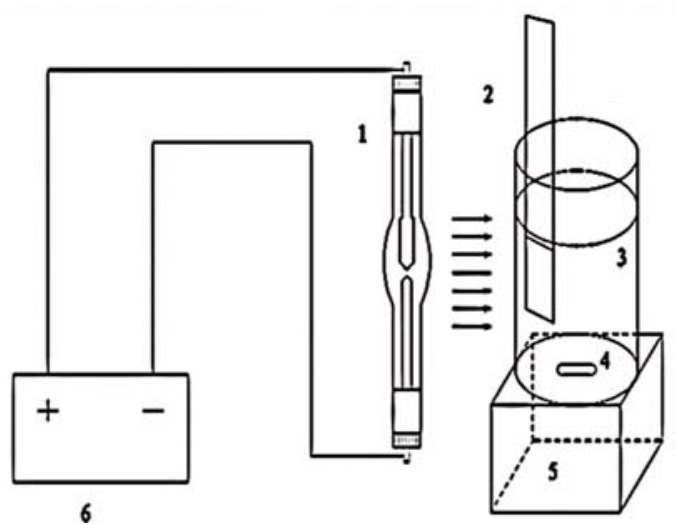

Figure 2. Diagram of the equipment for photocatalytic oxidation (1. Xenon lamp; 2. Working electrode; 3. Quartz reactor; 4. Stirrer; 5. Magnetic stirrer and 6. Power supply)

\section{RESULTS AND DISCUSSION}

\section{Photoelectrode characterization}

\section{SEM analysis}

The collected samples were observed by using a field emission scanning electron microscope, Figure 3, which showed the typical SEM images of the as-prepared bare $\mathrm{TiO}_{2}$ NTAs with the designated electrolyte EG type, SS type, AS type and SF type. This illustrated that the nanotubes fabricated with the use of an Ethylene Glycol electrolyte mixture have highly ordered nanotubular structures, which possessed an average inner diameter of around $120 \mathrm{~nm}$ and a wall thickness of $20 \mathrm{~nm}$ as shown in Figure 3(a). Nanotubes fabricated using a sodium sulfate electrolyte mixture showed similar morphological properties as Figure 3(b). The tubes fabricated with Ammonium sulfide showed a slightly unorganized tubular structure as seen in Figure 3(c) and, the nanotubes fabricated via anodization in a sodium fluoride mixture electrolyte are shown in Figure 3(d). The SEM images illustrated that the tubular structure of the fabricated nanotubes is fuzzy and fragile with signs of instability that result in different crystallization intensity due to the difference in heat effects on the nanostructures during the annihilation process. These differences in the tubular structures affect the ratio of the surface and volume which lead to the differences in the light harvesting properties.

Thus, XRD analysis has been performed on the surface of the titanium foils to investigate their crystalline phase and DRS tests were used to investigate the light harvesting properties. 


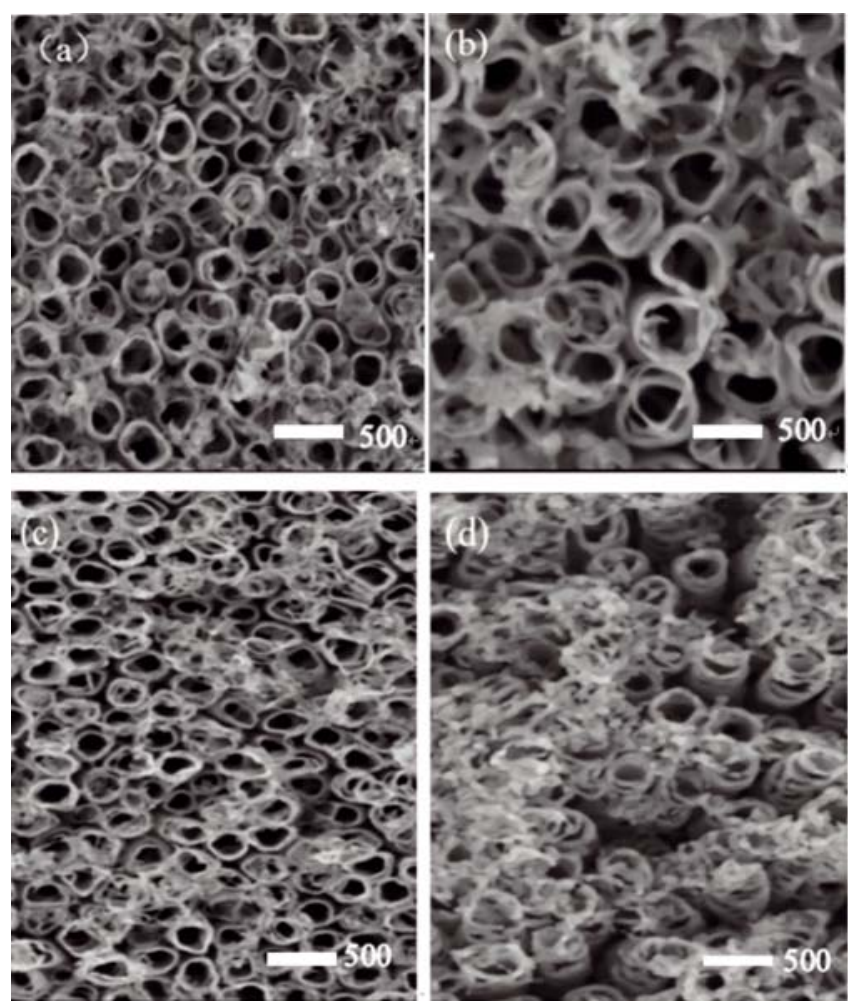

Figure 3. SEM analysis (a) Nanotubes EG type, (b) Nanotubes SS type, (c) Nanotubes AS type, and (d) Nanotubes SF type

\section{XRD and DRS analysis}

XRD patterns of the $\mathrm{TiO}_{2}$ NTAs samples were performed and are shown in Figure 4. All the crystalline phases could be indexed from their corresponding characteristic peaks using the anatase phase (JCPDS No. 21-1272), rutile (JCPDS NO. 21-1276) and Ti metal phase (JCPDS NO. 44-1294) , $^{30}$ in which these were distinctly marked with $\mathrm{A}, \mathrm{R}$ and $\mathrm{T}$ in the XRD patterns, respectively. Previous researchers discovered the significance of anatase crystals and distinguished its superior properties in harvesting light over rutile crystals $^{31}$. The test stated that photoelectrodes prepared by the mentioned electrolyte mixtures exhibited different diffraction peaks, especially regarding the anatase peaks (101), (200), (105), (204) and (215) which illustrated the ability of photoelectrodes with a high ratio of anatase crystals having the best light harvesting properties, which is supported by the DRS test shown in Figure 5. This illustrates that photoelectrodes fabricated in Ethylene glycol exhibit both UV light $(\lambda<400 \mathrm{~nm})$ and intense visible light absorption ranging from 400 to $800 \mathrm{~nm}$. The UV light absorption was attributed to the intrinsic band gap of bare $\mathrm{TiO}_{2}$, while the visible absorption was likely caused by the several aspects including the trapped charge carriers or some colored centers, as well as the absorption of incident light by the nanotubes ${ }^{32}$. This illustrates the importance of the quality of the crystalline structure for in the light absorption process.

The band gap of $\mathrm{TiO}_{2}$ NTAs can be calculated through the following Kubelka-Munk equation ${ }^{33}$ :

$(\alpha h v)=A\left(h v-E_{g}\right)^{n / 2}$

Where $v, \alpha, E g$, and $A$ are the absorption coefficient, the light frequency, the band gap, and constant, respectively. Among them, $n$ depends on the characteristics of the transition in a semiconductor, such as direct transition where $\mathrm{n}=1$ or indirect transition where $\mathrm{n}=4$.

\section{Rhodamine B degradation performance}

Organic dyes have often been chosen as a representative pollutant to evaluate PC performance. Thus, in this study, the degradation of $\mathrm{RhB}$ was used to evaluate PC performances of the fabricated $\mathrm{TiO}_{2}$ NTAs photoelectrodes. Direct photolysis or adsorption in the dark of $\mathrm{RhB}(<3 \%)$ was so low that it could be neglected. Compared with PC efficiencies, the removal of the PC performances of $\mathrm{TiO}_{2}$ NTAs were different in the four types of the fabricated $\mathrm{TiO}_{2}$ NTAs photoelectrodes. The quality of the tubular structure illustrated in the SEM

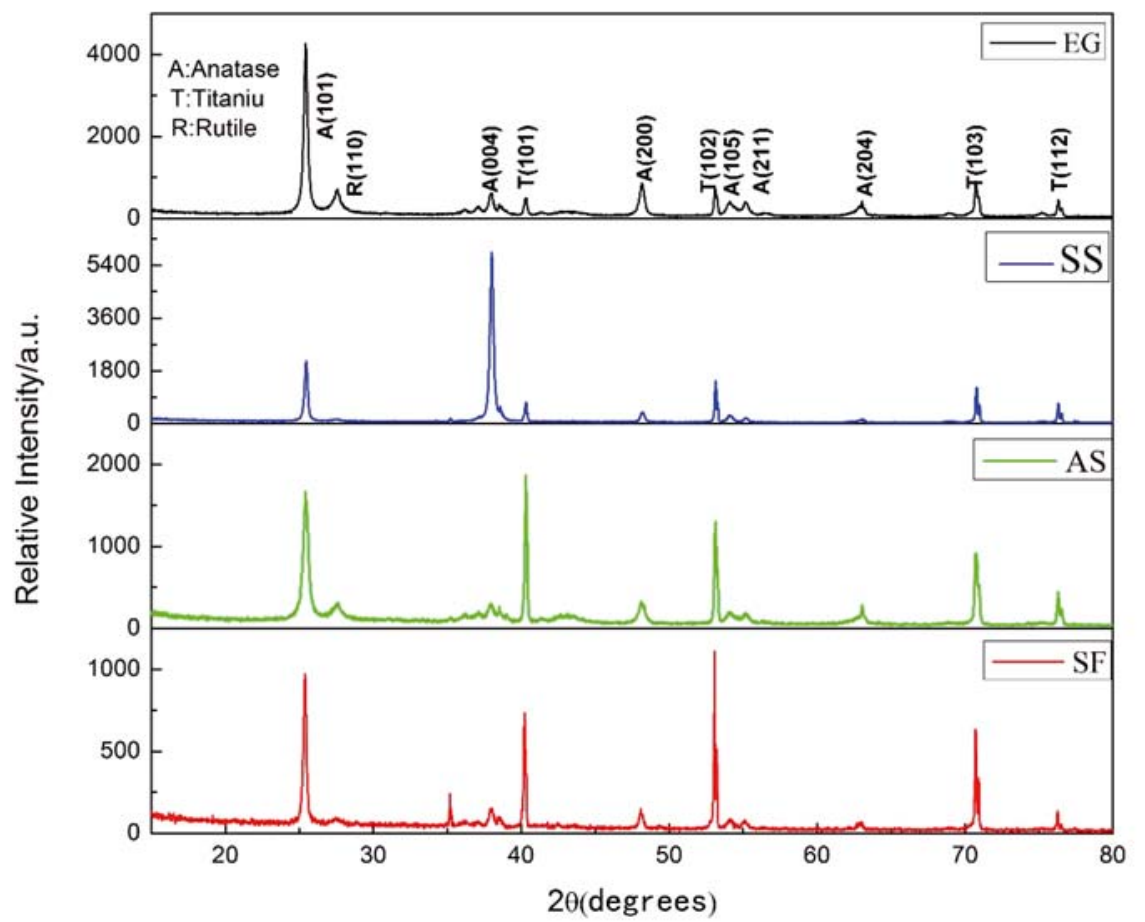

Figure 4. XRD patterns of the fabricated $\mathrm{TiO}_{2}$ NTAs. (1) EG-type, (2) SS-type, (3) AS-type and (4) SF-type 


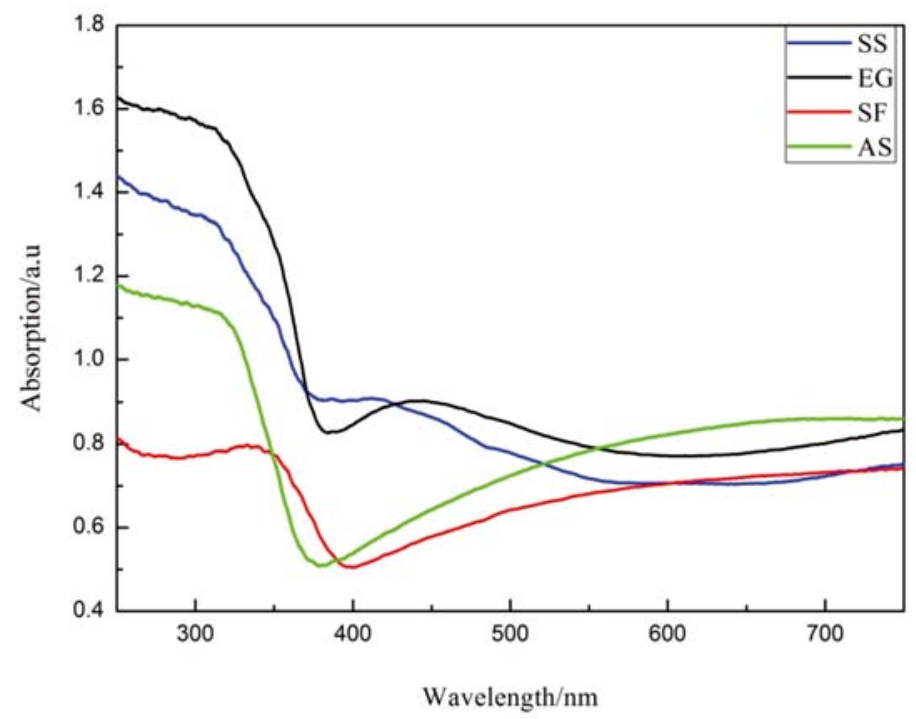

Figure 5. UV-Visible light absorption DRS patterns

test and crystallization formation indicated in the XRD test show the intensity value of anatase crystals to rutile crystals. The difference among the photoelectrodes fitted well with the results of the degradation efficiency of each type of the photoelectrodes. The degradation efficiencies of the collected samples were estimated using the following equation ${ }^{34}$ :

$\mathrm{DE}=\frac{C_{0}-C_{t}}{C_{0}} \times 100$

The degradation efficiencies of the EG-type photoelectrode, SS-type photoelectrode, AS-type photoelectrode and SF-type photoelectrode samples range in the following descending order: EG-type PC $>$ SS-type $\mathrm{PC}>$ AS-type $\mathrm{PC}>$ SF-type $\mathrm{PC}$. $\mathrm{TiO}_{2}$ fabricated via anodization in the Ethylene Glycol electrolyte mixture exhibit the highest PC performance in regards to the degradation of $\mathrm{RhB}$ than the other types, which are $88 \%, 83 \%, 58 \%$ and $53 \%$ in the 2 hour illumination period, as shown in Figure 6.

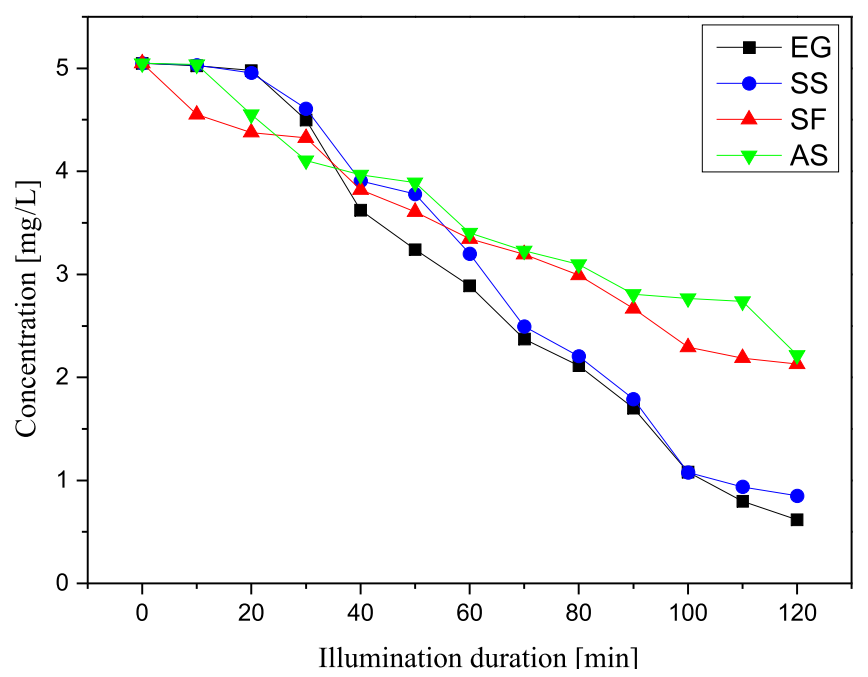

Figure 6. RHB Degradation ratio during the illumination process

The high-efficiency ratio is attributed to the perfect tubular structure which has the highest surface and volume ration while the crystallization quality at $500^{\circ} \mathrm{C}$ has superior intense light harvesting properties which directly contribute to the photodegradation efficiency of $\mathrm{RhB}$ due to the high production rate of $\cdot \mathrm{OH}$ and $\mathrm{O}_{2}$ radicals. The degradation rate of $\mathrm{RhB}$ fitted well with the pseudo-first-order kinetics function within $120 \mathrm{~min}$ as shown in Figure 7 according to the Langmuir-Hinshelwood $(\mathrm{L}-\mathrm{H})$ model which is shown in the following equation ${ }^{35}$ :

$\ln \left(\frac{C}{c_{0}}\right)=-k_{a p p^{t}}$

It is notable that $\mathrm{TiO}_{2}$ NTAs fabricated in Ethylene glycol electrolyte mixture exhibited superior photocatalytic performances than the $\mathrm{TiO}_{2}$ NTAs fabricated in the other mentioned electrolyte mixtures under parallel conditions. Moreover, it can be induced that the $\mathrm{TiO}_{2}$ NTAs photoanode fabricated in ethylene glycol displayed the highest photocatalytic activity with a constant rate of $0.0157 \mathrm{~min}^{-1}$ under Xenon light irradiation. The superior PC performance can be attributed to the intense visible light absorbance along with efficient mobility and separation of photogenerated charge carriers.

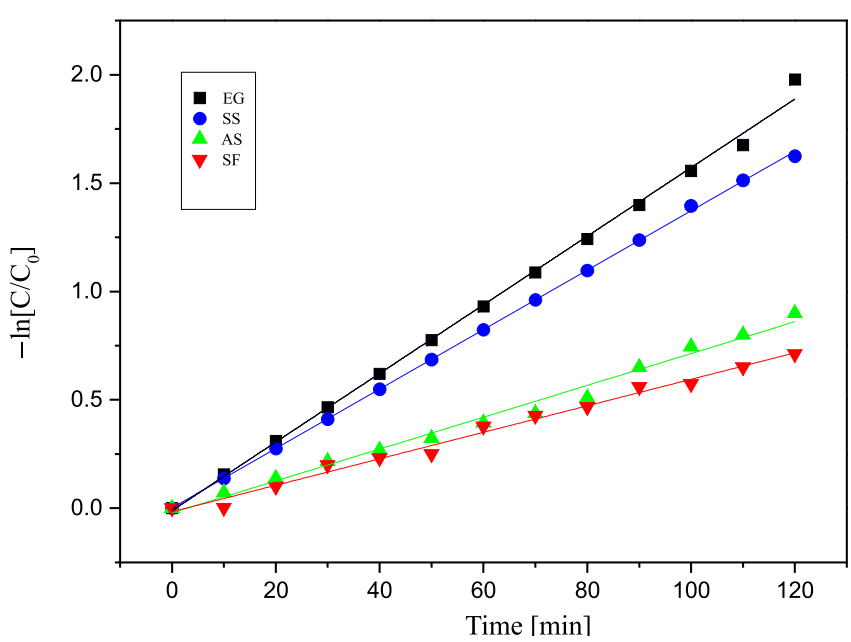

Figure 7. $\mathrm{PC}$ evolution curves of $\mathrm{RhB}$ solution on as-prepared bare $\mathrm{TiO}_{2}$ NTAs photoelectrodes under $120 \mathrm{~min}$ of xenon light illumination

The results show that the photocatalytic degradation of Rhodamine B of these samples can be described by the first order kinetic model which are mentioned above. 
Table 1. Photoelectrocatalytic degradation kinetics of Rhodamine B using $\mathrm{TiO}_{2}$ NTAs photoelectrodes fabricated in different electrolyte mixtures

\begin{tabular}{|l|c|c|c|}
\hline Samples & First order reaction kinetics equation & $\begin{array}{c}\text { Apparent rate } \\
\text { constants [k] }\end{array}$ & Correlation coefficient [R ${ }^{2}$ ] \\
\hline EG & $y=0.0157 x+0.00011$ & 0.0157 & 0.9973 \\
\hline SS & $y=0.0137 x+0.00017$ & 0.0137 & 0.9997 \\
\hline SF & $y=0.0071 x+0.00031$ & 0.0071 & 0.9865 \\
\hline AS & $y=0.0059 x+0.00025$ & 0.0059 & 0.9885 \\
\hline
\end{tabular}

The linear relationship with the irradiation time, the calculated rate constants and the corresponding correlation coefficients are as listed in Table 1.

In order to investigate the photocatalytic stability of the fabricated photoelectrodes which is important for their practical application because they can be regenerated and salvaged, the concentration and stability of the solution of the designated organic pollutant (Rhodamine B) was kept in the dark and saved in black agar containers. Before administering the photodegradation process the mixture is agitated for 20 minutes inside an isolated metal box to reach a state of adsorption-desorption equilibrium. Afterwards, the photoelectrode is fixed in the photoreactor and illuminated for 2 hours. This process was repeated for seven successive-cycles for each fabricated/type photoelectrode. The results show that for the first 5 cycles the catalyst exhibited similar catalytic performance without any significant deactivation, revealing its high stability after multiple reuses. Then on the
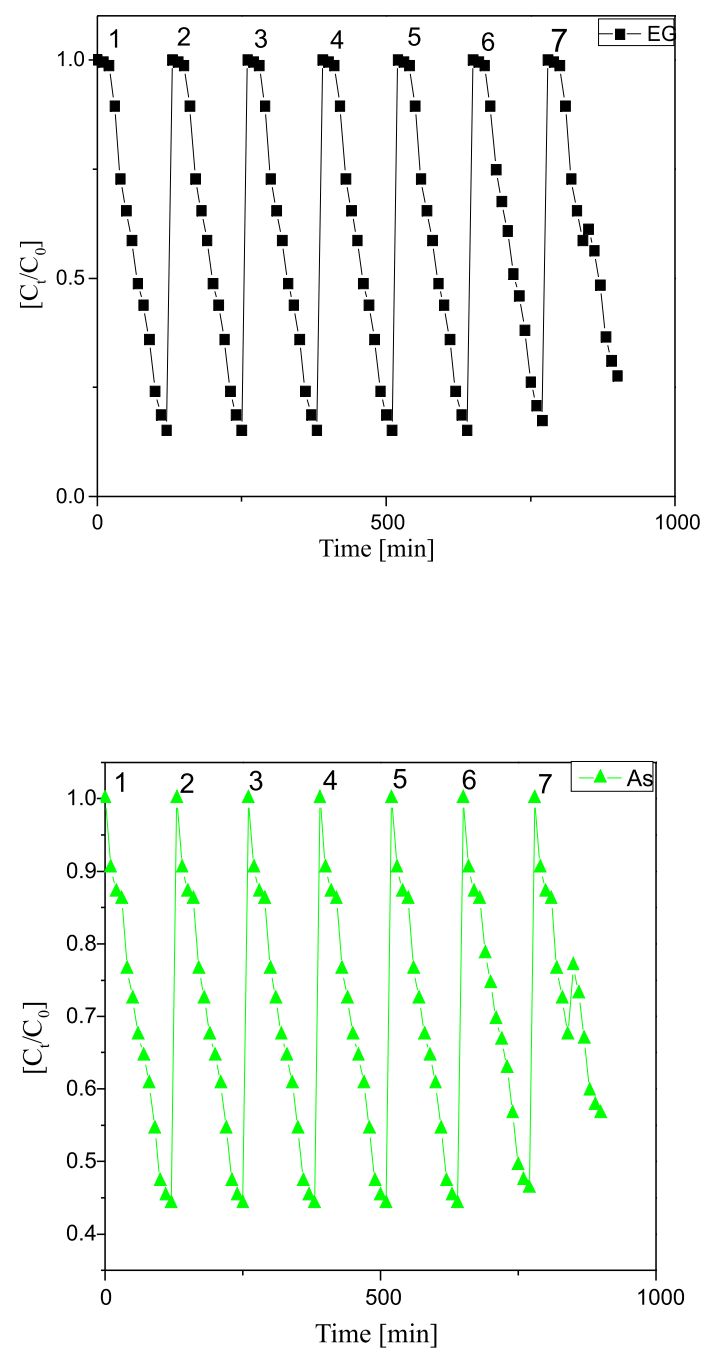

sixth cycle it deteriorated slightly, and at the end of the seventh cycle, the change becomes remarkably noticeable especially for the AS and SF photoelectrode types as shown in Figure 8.

\section{Electrolytes $\mathbf{p H}$}

The $\mathrm{pH}$ test was performed on the electrolytes mixtures to investigate their acidity as shown in the following Table 2.

Table 2 shows relatively similar $\mathrm{pH}$ values which indicate that the $\mathrm{pH}$ of the electrolyte mixtures has an identical effect on the formation of the nanotube arrays.

Table 2. $\mathrm{pH}$ values of the electrolyte mixtures

\begin{tabular}{|l|c|}
\hline Electrolyte & $\mathrm{pH}$ \\
\hline Ethylene glycol mixture & 7.41 \\
\hline Sodium sulfate & 7.17 \\
\hline Ammonium sulfate & 6.74 \\
\hline Sodium fluoride & 7.31 \\
\hline
\end{tabular}
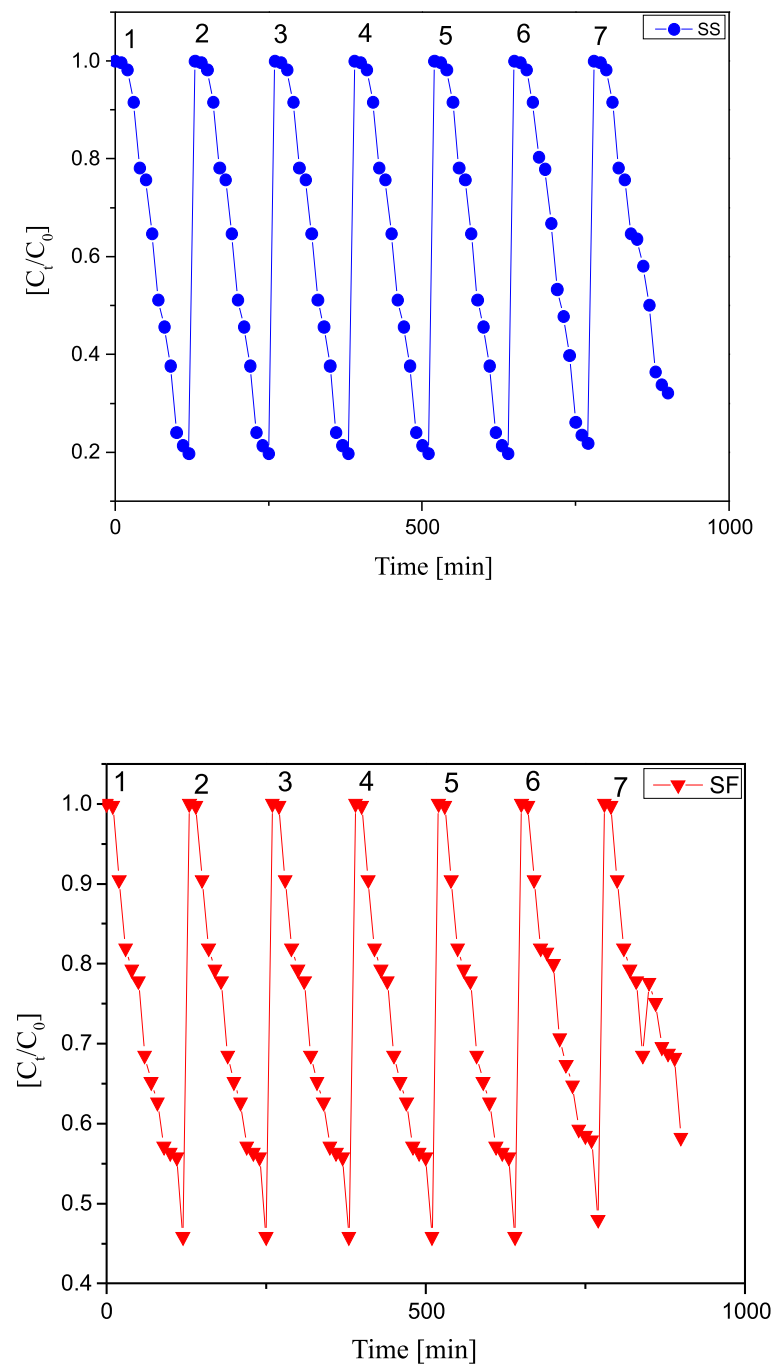

Figure 8. Photocatalyst stability test of as-prepared bare $\mathrm{TiO}_{2} \mathrm{NTAs}$ photoelectrodes (1) EG-type, (2) SS-type, (3)AS-type and (4) SF-type 


\section{CONCLUSION}

In this work, bare $\mathrm{TiO}_{2}$ NTAs photoelectrodes were prepared by anodization using four different mixtures of electrolytes (ethylene glycol mixture, sodium sulfate mixture, ammonium sulfide mixture and sodium fluoride mixture), which are claimed to have good potential for forming highly ordered $\mathrm{TiO}_{2}$ nanotube arrays that possess significant photocatalytic properties. This research has found that photoelectrodes fabricated using anodization in the said electrolyte mixtures exhibit different characterizations illustrated via analytical tests performed on the surface of the fabricated electrodes such as SEM and XRD. The tests indicated that photoelectrodes fabricated in the ethylene glycol mixture electrolyte and sodium sulfate mixture electrolytes display finer tubular shapes than the photoelectrodes fabricated in the ammonium sulfide mixture and sodium fluoride mixture. XRD tests have shown that EG-type photoelectrodes possess a high rate of anatase crystals over rutile crystals and have a high visible light harvesting range from 1600 to $2000 \mathrm{~nm}$ which suggests superior photocatalytic properties according to C. Byun's research ${ }^{32}$. Thus they exhibit superior photodegradation properties, while the photoelectrodes fabricated in sodium sulfate exhibit slightly lesser photodegradation properties. The average degradation ratio for fabricated $\mathrm{TiO}_{2}$ is shown in Figure 9 .

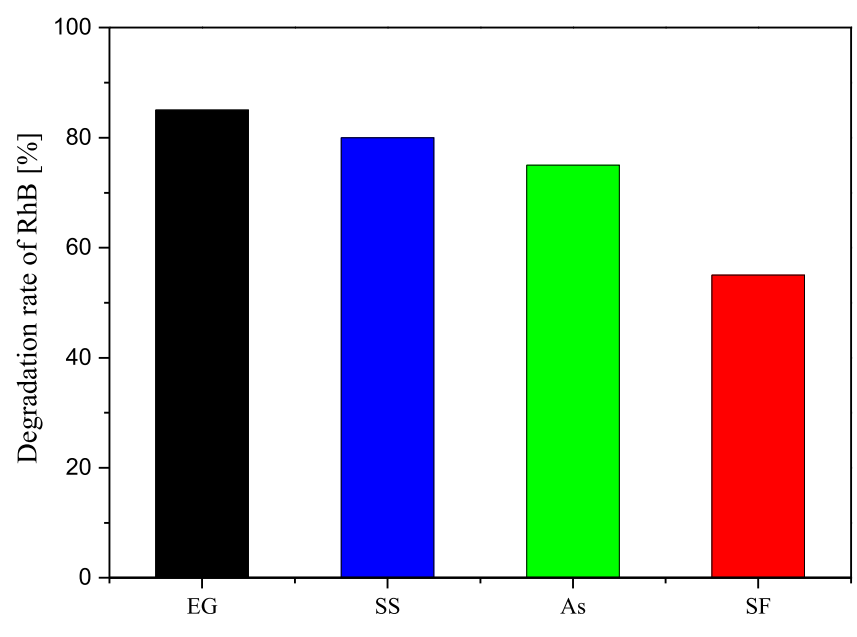

TiO2 NTAs [Ti foils]

Figure 9. The photocatalytic degradation efficiency of the fabricated bare $\mathrm{TiO}_{2}$ NTAs in different electrolyte mixtures

In addition, the $\mathrm{pH}$ of the electrolyte mixtures has a similar level which indicates that the acidity of the mixture has no direct effect on the formation of the nanotubes. The PC degradation of $\mathrm{RhB}$ results fitted well with the results of the performed photocatalytic analysis.

\section{ACKNOWLEDGMENTS}

This work was supported by the National Natural Science Foundation of China (51178138), the National Creative Research Groups of China (51121062) and the State Key Laboratory of Urban Water Resources and Environment (2010DX03).

\section{LITERATURE CITED}

1. Chen, Q., Liu, H., Xin, Y., Cheng, X., Zhang, J., Li, J., Wang, P. \& Li, H. (2013). Controlled anodic growth of $\mathrm{TiO}_{2}$ nanobelts and assessment of photoelectrochemical and photocatalytic properties. Electrochim. Acta, 99, 152-160. DOI: 10.1016/j.electacta.2013.03.032.

2. Cheng, X., Liu, H., Chen, Q., Li, J. \& Wang, P. (2013). Construction of $n, s$ codoped $\mathrm{TiO} 2$ ncs decorated $\mathrm{TiO} 2$ nano-tube array photoelectrode and its enhanced visible light photocatalytic mechanism. Electrochim. Acta, 103, 134-142. DOI: 10.1016/j.electacta.2013.04.072.

3. Yao, Y., Li, K., Chen, S., Jia, J., Wang, Y. \& Wang, H. (2012). Decolorization of rhodamine b in a thin-film photoelectrocatalytic (pec) reactor with slant-placed $\mathrm{TiO} 2$ nanotubes electrode. J. Chem. Eng. 187, 29-35. DOI: 10.1016/j. cej.2012.01.056.

4. Sun, S., Chen, C., Sun, J., Peng, Q., Lü, K. \& Deng, K. (2013). Enhancement of catalytic degradation of rhodamine b under sunlight with au loading TiO2 nanotube arrays. J. Procedia Environ. Sci. 18, 620-624. DOI: 10.1016/j.proenv.2013.04.085.

5. Cheng, X., Liu, H., Chen, Q., Li, J. \& Wang, P. (2013). Preparation and characterization of palladium nano-crystallite decorated $\mathrm{TiO} 2$ nano-tubes photoelectrode and its enhanced photocatalytic efficiency for degradation of diclofenac. J. Hazard. Mater. 254, 141-148. DOI: 10.1016/j.jhazmat.2013.03.062.

6. Yu, X., Zhang, Y. \& Cheng, X. (2014). Preparation and photoelectrochemical performance of expanded graphite/TiO2 composite. Electrochim. Acta 137, 668-675. DOI: 10.1016/j. electacta.2014.06.027.

7. Zhong, H., Shaogui, Y., Yongming, J. \& Cheng, S. (2009). Microwave photocatalytic degradation of rhodamine b using $\mathrm{TiO} 2$ supported on activated carbon: Mechanism implication. J. Environ. Sci. 21(2), 268-272. DOI: 10.1016/ S1001-0742(08)62262-7.

8. Fan, M., Hu, S., Ren, B., Wang, J. \& Jing, X. (2013). Synthesis of nanocomposite $\mathrm{TiO} 2$ /zro 2 prepared by different templates and photocatalytic properties for the photodegradation of rhodamine b. J. Pow. Technol. 235, 27-32. DOI: 10.1016/j.powtec.2012.09.042.

9. Cheng, X., Pan, G. \& Yu, X. (2015). Visible light responsive photoassisted electrocatalytic system based on cds ncs decorated $\mathrm{TiO} 2$ nano-tube photoanode and activated carbon containing cathode for wastewater treatment. Electrochim. Acta. 156, 94-101. DOI:10.1016/j.electacta.2015.01.042.

10. Chen, Q., Liu, H., Xin, Y. \& Cheng, X. (2013). TiO2 nanobelts-effect of calcination temperature on optical, photoelectrochemical and photocatalytic properties. Electrochim. Acta. 111, 284-291. DOI: 10.1016/j.electacta.2013.08.049.

11. Momeni, M. (2015). Fabrication of copper decorated tungsten oxide-titanium oxide nanotubes by photochemical deposition technique and their photocatalytic application under visible light, Appl. Surf. Sci. 357, 160-166. DOI: 10.1016/j. apsusc.2015.09.015.

12. Momeni, M., Hakimian, M. \& Kazempour A. (2015). In-situ manganese doping of $\mathrm{TiO} 2$ nanostructures via singlestep electrochemical anodizing of titanium in an electrolyte containing potassium permanganate: A good visible-light photocatalyst. Ceram. Int. 41, 13692-13701. DOI: 10.1016/j. ceramint.2015.07.158.

13. Momeni, M. \& Nazari, Z. (2016). Preparation of TiO2 and $\mathrm{WO} 3-\mathrm{TiO} 2$ nanotubes decorated with $\mathrm{PbO}$ nanoparticles by chemical bath deposition process: A stable and efficient photocatalyst. Ceram. Int. 42, 8691-8697. DOI: 10.1016/j. ceramint.2016.02.103.

14. Cheng, X., Yu, X. \& Xing, Z. (2013). Synthesis and characterization of $\mathrm{c}-\mathrm{n}$-s-tridoped $\mathrm{TiO} 2$ nano-crystalline photocatalyst and its photocatalytic activity for degradation of rhodamine b. J. Phys. Chem. Sol. 74(5), 684-690. DOI: 10.1016/j.jpcs.2013.01.004. 
15. Cao, G.J., Bo, C., Wang, W.Q., Tang, G.Z., Feng, Y.C. \& Wang, L.P. (2014). Fabrication and photodegradation properties of $\mathrm{TiO} 2$ nanotubes on porous ti by anodization. J. Trans. Nonferrous Met. Soc. China 24(8), 2581-2587. DOI: 10.1016/ S1003-6326(14)63386-0.

16. Momeni, M., Mirhosseini, M. \& Chavoshi, M. (2016). Growth and characterization of Ta2O5 nanorod and WTa2O5 nanowire films on the tantalum substrates by a facile onestep hydrothermal method. Ceram. Int. 42, 9133-9138. DOI: 10.1016/j.ceramint.2016.03.002.

17. Bai, J., Zhou, B., Li, L., Liu, Y., Zheng, Q., Shao, J., Zhu, X., Cai, W., Liao, J. \& Zou, L. (2008). The formation mechanism of titania nanotube arrays in hydrofluoric acid electrolyte. J. Mater. Sci. 43(6), 1880-1884. DOI: 10.1007/ s10853-007-2418-8.

18. Momeni, M. \& Ghayeb, Y. (2016). Fabrication, characterization and photocatalytic properties of $\mathrm{Au} / \mathrm{TiO} 2-\mathrm{WO} 3$ nanotubular composite synthesized by photo-assisted deposition and electrochemical anodizing methods, J. Mol. Catal. A Chemical. 417, 107-115. DOI: 10.1016/j.molcata.2016.03.024.

19. Momeni, M. \& Ghayeb, Y. (2016). Fabrication, characterization and photoelectrochemical performance of chromiumsensitized titania nanotubes as efficient photoanodes for solar water splitting, J. Sol. Stat. Electrochem. 20, 683-689, DOI: 10.1007/s10008-015-3093-3.

20. Momeni, M. \& Ghayeb, Y. (2016). Cobalt modified tungsten-titania nanotube composite photoanodes for photoelectrochemical solar water splitting. J. Mater Sci: Mater Electron. 27, 3318-3327. DOI: 10.1007/s10854-015-4161-2.

21. Momeni, M., Mirhosseini, M., Chavoshi, M. \& Hakimizade, A. (2016). The effect of anodizing voltage on morphology and photocatalytic activity of tantalum oxide nanostructure. J. Mater Sci: Mater Electron. 27, 3941-3947. DOI: 10.1007/ s10854-015-4246-y.

22. Momeni, M., Hakimian, M. \& Kazempour, A. (2016). Preparation and characterisation of manganese-TiO2 nanocomposites for solar water splitting. Surf. Eng. 32(7), 514-519. DOI: 10.1179/1743294415Y.0000000073.

23. Momeni, M., Ghayeb, Y. \& Ghonchegi, Z. (2015). Fabrication and characterization of copper doped $\mathrm{TiO} 2$ nanotube arrays by in situ electrochemical method as efficient visiblelight photocatalyst. Ceram. Int. 41, 8735-8741. DOI: 10.1016/j. ceramint.2015.03.094.

24. Momeni, M. \& Ghayeb, Y. (2015). Photoelectrochemical water splitting on chromium-doped titanium dioxide nanotube photoanodes prepared by single-step anodizing. J. Alloys Compd.. 637, 393-400. DOI: 10.1016/j.jallcom.2015.02.137.

25. Momeni, M., Ghayeb, Y. \& Davarzadeh, M. (2015). Single-step electrochemical anodization for synthesis of hierarchical WO3-TiO2 nanotube arrays on titanium foil as a good photoanode for water splitting with visible light. J. Electroanal. Chem. 739, 149-155. DOI: 10.1016/j.jelechem.2014.12.030.

26. Xu, C.L., Bao, S.J., Kong, L.B., Li, H. \& Li, H.L. (2006). Highly ordered $\mathrm{MnO}_{2}$ nanowire array thin films on ti/si substrate as an electrode for electrochemical capacitor. J. Solid State Chem. 179(5), 1351-1355. DOI: 10.1016/j.jssc.2006.01.058.

27. Sklar, G., Singh, H., Mahajan, V., Gorhe, D., Namjoshi, S. \& LaCombe, J. (2005). Nanoporous titanium oxide morphologies produced by anodizing of titanium. MRS Proceedings: Cambridge Univ Press p. R1 2 DOI: 10.1557/PROC-876-R1.2.

28. Cheng, X., Liu, H., Chen, Q., Li, J. \& Wang, P. (2014). Preparation of graphene film decorated $\mathrm{TiO} 2$ nano-tube array photoelectrode and its enhanced visible light photocatalytic mechanism. Carbon 66, 450-458. DOI: 10.1016/j. carbon.2013.09.021.

29. Tian, C.Y., Zhao, W.W., Wang, J., Xu, J.J. \& Chen, H.Y. (2012). Amplified quenching of electrochemiluminescence from cds sensitized $\mathrm{TiO} 2$ nanotubes by cdte-carbon nanotube composite for detection of prostate protein antigen in serum. J. Analyst 137(13), 3070-3075. DOI: 10.1039/C2AN35493D.
30. Al-Sammarraie, A.M.A. (2014). The role of anodizing potentials in making $\mathrm{TiO} 2$ nanotubes in (ethylene glycol / nh $4 \mathrm{f} /$ water) electrolyte. Arch. Appl. Sci. Res. 11-13.

31. Okada, M., Tajima, K., Yamada, Y. \& Yoshimura, K. (2012). Self-organized formation of short $\mathrm{TiO} 2$ nanotube arrays by complete anodization of ti thin films. J. Phys. Proc. 32, 714-718. DOI: 10.1016/j.phpro.2012.03.622.

32. Byun, C., Jang, J., Kim, I., Hong, K. \& Lee, B.W. (1997). Anatase-to-rutile transition of titania thin films prepared by mocvd. J. Mater. Res. Bull. 32(4), 431-440. DOI: 10.1016/ S0025-5408(96)00203-6.

33. Merabet, S., Robert, D., Weber, J.V., Bouhelassa, M. \& Benkhanouche, S. (2009). Photocatalytic degradation of indole in uv/tio2: Optimization and modelling using the response surface methodology (rsm). J. Environ. Chem. Lett. 7(1), 45-49. DOI: $10.1007 / \mathrm{s} 10311-008-0137-2$.

33. Spadavecchia, F., Cappelletti, G., Ardizzone, S., Bianchi, C.L., Cappelli, S., Oliva, C., Scardi, P., Leoni, M. \& Fermo, P. (2010). Solar photoactivity of nano-n-TiO2 from tertiary amine: Role of defects and paramagnetic species. J. Appl. Catal. 96(3), 314-322. DOI: 10.1016/j.apcatb.2010.02.027.

34. Khataee, A., Arefi-Oskoui, S., Fathinia, M., Esmaeili, A., Hanifehpour, Y., Joo, S.W. \& Hamnabard, N. (2015). Synthesis, characterization and photocatalytic properties of er-doped pbse nanoparticles as a visible light-activated photocatalyst. J. Mol. Catal. A: Chem. 398, 255-267. DOI: 10.1016/j. molcata.2014.11.009.

35. Hoffmann, M.R., Martin, S.T., Choi, W. \& Bahnemann, D.W. (1995). Environmental applications of semiconductor photocatalysis. J. Chem. Rev. 95(1), 69-96. DOI: 10.1021/ cr00033a004. 